\title{
UTERINE PERIVASCULAR EPITHELIOID CELL TUMOUR AND ASSESSMENT OF ITS MALIGNANT POTENTIAL
}

Singapore Med J 2015; 56(9): 531 doi: 10.11622/smedj.2015143

Dear Sir,

Perivascular epithelioid cell tumours (PEComas) are relatively uncommon mesenchymal tumours. ${ }^{(1,2)}$ The uterus is the more frequently reported site of origin of PEComas, ${ }^{(2,3)}$ and to the best of our knowledge, there have been approximately 60 cases of uterine PEComas reported in the literature. ${ }^{(3,4)}$ Uterine PEComas belong to the same family as angiomyolipomas, lymphangioleiomyomatosis and clear cell sugar tumours, characterised by a myomelanocytic immunohistochemical phenotype. ${ }^{(1,3)}$ Recent studies have described several histological features of the tumour that portend its aggressive behaviour, but have also shown possible therapeutic management for PEComas, namely by means of mammalian target of rapamycin inhibitors; ${ }^{(4)}$ these findings make recognition of this tumour more imperative than before.

We herein report a case of a 45-year-old woman who presented with menorrhagia and had a history of complex partial seizures and renal angiomyolipoma. A uterine fundal lesion was detected sonographically, and laparoscopic hysterectomy and bilateral salpingectomy were performed. Grossly, the lesion had an ill-defined whitish appearance admixed closely with blood vessels. Two other lesions were also admixed closely within the uterine isthmus and the subserosa. Histological examination of the uterine fundal lesion revealed epithelioid tumour cells with clear-to-pale cytoplasm and ovoid nuclei with open chromatin pattern. The epithelioid cells were surrounded by spindled cells with similar cytological features. The lesion displayed infiltrative borders and tumour multinucleated giant cells were discerned within more cellular areas. However, mitoses were not observed. The lesions in the other two areas (i.e. the uterine isthmus and subserosa) also revealed circumscribed aggregates of similar tumour cells. The tumour cells exhibited the typical myomelanocytic immunophenotype by expressing smooth muscle actin, desmin, HMB-45 and Melan-A. The cell proliferative index by the Ki-67 marker was less than 1\%. Based on the findings, it was concluded that all three lesions were uterine PEComas. In view of the patient's recently diagnosed renal angiomyolipoma and the history of complex partial seizures with radiologically detected calcified tubers, the possibility of tuberous sclerosis complex was raised.

The presence of infiltrative margins, as well as scattered tumour multinucleated giant cells, portends the more aggressive behaviour of the tumour (Fig. 1). There have been reports of uterine PEComas exhibiting aggressive behaviour and even causing distant metastases. ${ }^{(2)}$ As such, various classification systems for the stratification of PEComas based on their malignancy potential have been proposed. In our case, the tumour sizes were small and lacked tumour necrosis, lymphovascular invasion and mitoses. The largest lesion had an ill-defined border; additionally, there were scattered tumour multinucleated giant cells within the cellular areas of the lesion. As such, we felt that the tumour in our case was best classified as PEComa of uncertain malignancy potential. It is unclear how this tumour will behave, but appropriate close surveillance is recommended until further studies shed more light on the biological behaviour of this category of PEComas. ${ }^{(4)}$

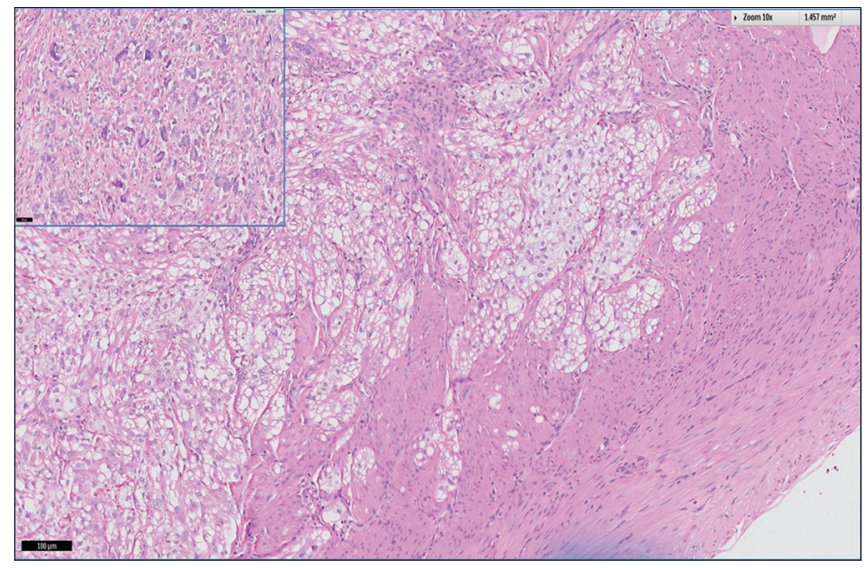

Fig. 1 Photomicrograph shows islands of epithelioid tumour cells with clear-to-pale cytoplasm permeating into the adjacent myometrium (Haematoxylin \& eosin, $\times 100$ ) and scattered tumour multinucleated giant cells (Haematoxylin \& eosin, $\times 200$ ).

Yours sincerely,

Wei Qiang Leow ${ }^{1}$, Sathiyamoorthy $\underline{\text { Selvarajan }}^{1}$

${ }^{1}$ Department of Pathology, Singapore General Hospital, Singapore. leow.wei.qiang@sgh.com.sg

\section{References}

1. Bleeker JS, Quevedo JF, Folpe AL. Malignant perivascular epithelioid cell tumor of the uterus. Rare Tumors 2012; 4:e14.

2. Armah HB, Parwani AV. Malignant perivascular epithelioid cell tumor (PEComa) of the uterus with late renal and pulmonary metastases: a case report with review of the literature. Diagn Pathol 2007; 2:45.

3. Fadare O. Uterine PEComa: appraisal of a controversial and increasingly reported mesenchymal neoplasm. Int Semin Surg Oncol 2008; 5:7.

4. Schoolmeester JK, Howitt BE, Hirsch MS, et al. Perivascular epithelioid cell neoplasm (PEComa) of the gynecologic tract: clinicopathologic and immunohistochemical characterization of 16 cases. Am J Surg Pathol 2014; 38:176-88. 